\title{
Dari Tari ke Musik: Pembentukan Musik Suita Pada Era Musik Barok
}

\author{
Pola Martiana \\ Universitas Padjadjaran \\ (ana.pola.martiana@gmail.com)
}

\begin{abstract}
Suite as a musical form was composed by many Baroque composers. It was built and based on dances which is popular in the Renaissance or Baroque eras. This paper tries to understand the way composers adapt one form of art to another form, that is from dance to music, which is widely known as ecranisation. To grasp it in depth, this paper firstly describes what dance musics consist in suite. Secondly, it describes the dances which form the dance music. To make it clear, it also describes the essence of dance that makes it possible the transformation from dance to music. The result shows that the transformation does happen because of the abstract essence in dance was transformed into notes in music. This process is revealed by using the method of phenomenology of Maurice MerleauPonty.
\end{abstract}

Keywords: music, dance, suite, ecranisation, inspiration, transformation, movement, note

\begin{abstract}
ABSTRAK
Musik suita yang banyak digubah pada era musik Barok dibangun dari sejumlah gerakan musik yang berasal-usul dari tari-tari yang populer di era Renaisans/ Barok. Tulisan ini berusaha memahami bagaimana komponis mengalihwahanakan seni yang ada: dari tari ke musik. Untuk memahami kejadian itu, penulis memaparkan gerakan musik apa saja yang terdapat di dalam suita, setelah itu dipaparkan tari-tari yang menjadi sumber inspirasi komponis. Setelah didapatkan gambaran lengkap mengenai musik dan tari yang relevan, perlulah dipahami apa yang terdapat di dalam tari sehingga bisa diserap oleh komponis untuk kemudian dikeluarkan kembali dalam bentuk musik. Dari paparan itu terlihatlah bahwa transformasi dari tari ke musik hanya mungkin karena adanya transformasi gagasan abstrak yang terdapat di dalam tari untuk kemudian diekspresikan dalam bentuk nada-nada, dan hal itu semua hanya bisa dipahami dengan menggunakan metode fenomenologi dari Maurice Merleau-Ponty.
\end{abstract}

Kata kunci: musik, tari, suita, alih wahana, inspirasi, transformasi, gerakan, nada 


\section{PENDAHULUAN}

Di dalam sejarah musik Barat, setiap era di dalamnya memiliki sejumlah ciri yang unik yang menandakan secara jelas era tersebut. Ciri yang unik itu bisa berbentuk alat musik yang menonjol, dinamik musik yang umum terdapat di dalam musik, bentuk musik yang berkembang, keterkaitan yang erat dengan halhal non-musik/kemasyarakatan, dan sebagainya. Di dalam tulisan ini, era yang relevan dengan topik tulisan ini adalah era Barok.

Di dalam era Barok ada sebuah ciri yang tiada duanya dibandingkan dengan era-era lainnya. Ciri yang relevan itu adalah adanya musik tarian yang digubah oleh sejumlah komponis besar era itu. "Musik tarian" merupakan musik yang "disatukan di dalam sebuah 'album'" dan disebut dengan "suita". Di dalam sebuah suita ada sejumlah gerakan musik (musical movement) yang diinspirasikan oleh tari yang memang ada secara faktual dan aktual. Gerakan musik di dalam suita sangat unik karena ia sangat sulit, kalau tidak bisa dikatakan "tidak bisa untuk mengiringi tarian yang faktual dan aktual itu". Gerakan musik itu adalah musik yang dihasilkan dari penggayaan gerakan tari (stylized dance music) - sebuah musik yang diinspirasikan oleh gaya tari.

Tari adalah sebuah bentuk ekspresi manusia yang paling primordial. Ia berangkat dari apa yang ada dalam diri manusia yang paling abstrak, yang kemudian diterjemahkan dalam ekspresinya melalui kebertubuhannya. Sesuatu yang abstrak itu bisa berbentuk mood, emosi atau perasaan-perasaan spesifik lainnya. Dari sesuatu yang abstrak itu, keluarlah "terjemahannya" dalam bentuk tubuh yang bergerak - yang sifatnya empiris dan nyata. Itulah sebabnya dikatakan bahwa ciri yang paling unik dari tari adalah ketidakterlepasannya dari tubuh manusia.

Oleh karena begitu lekat dengan tubuh manusia, maka tak mengherankan bila tarian bisa menciptakan efek dramatis; tetapi sekaligus juga ia bisa terarah pada abstraksi. Dalam studi-studi mengenai estetika tari, pendekatan yang ada, di satu sisi, menekankan pada tubuh (penarinya), ${ }^{10}$ sedangkan yang kedua memandang tari sebagai "symbolic gestures".

Menurut penulis, pembentukan gerakan musik di dalam suita adalah karena memandang tari sebagai symbolic gestures. Gagasan tari sebagai symbolic gestures memandang tari sebagai sebuah seni yang sesungguhnya memiliki hakekat yang bersifat musikal; penari mengekspresikan diri melalui gerak (gesture), apa yang ia rasakan terhadap isi emosional musik yang menyebabkan ia menari. Dengan sudut pandang ini pula bisa dipahami bahwa tari itu sesungguhnya merupakan salah satu jenis dari seni plastis - ia dipandang sebagai "patung yang bergerak". "Patung" itu bergerak karena sebuah dorongan yang "mendesak-desak" di dalam dirinya. Dorongan itu adalah sesuatu yang bersifat musikal yang memenuhi bathin manusia. Kekuatan dorongan itu sedemikian luar biasanya, sehingga "patung" yang "netral" itu akhirnya bergerak secara tertentu mengikuti dorongan yang ada.

Itulah sebabnya, tari memiliki ilusi primer (primary illusion). Ilusi primer itu adalah gerakan (motion); ilusi primer itu dihadirkan melalui "patung" di atas. Tubuh akan tetap menjadi patung semata bila ia tidak mengalami transformasi; tubuh itu kemudian mentransformasikan diri melalui ekspresi gerak (gesture). Gesture harus dipahami dengan mengacu dan juga sekaligus tidak mengacu pada tubuh. Ia membentuk subject matter di dalam tari. Ini 
seperti halnya subject matter di dalam lukisan; subject matter di dalam lukisan dihasilkan dengan cara melihat dan sekaligus tidak melihat apa yang ada di permukaan lukisan. Dengan demikian, subject matter tari merupakan vital movement; bagi penari ia dialami sebagai tindakan (action) pengalaman kinetis, sedangkan bagi penonton ia dipandang sebagai visible motion yang bukan a motion of things.

Tulisan ini akan berbicara mengenai apa itu suita dan kemudian bagaimana asalusulnya dari gerakan tari sehingga ia akhirnya menjadi gerakan musik yang bahkan tidak bisa mengiringi tari yang menjadi asal-usul dari musik tersebut.

Suita adalah sebuah bentuk musik instrumental yang besar dari era Barok. Di sini penulis membedakan antara bentuk musik besar dan bentuk musik kecil - hal ini relevan dengan pembahasan mengenai suita itu sendiri. Yang disebut dengan bentuk musik kecil adalah bentuk musik individual, seperti halnya sebuah lagu di dalam musik populer. Sedangkan bentuk musik besar adalah gabungan dari sejumlah bentuk musik kecil - ini seperti halnya "album" di dalam musik populer. Seperti juga telah dikatakan di atas, sebagai sebuah bentuk musik besar ia sejajar dengan sonata di era Klasik.

Di dalam suita terdapat gerakangerakan musik yang utama. Gerakangerakan musik utama itu adalah gerakangerakan yang merupakan gerakan "obligatoris" sehingga sejumlah kumpulan gerakan musik tertentu bisa pantas disebut sebagai sebuah suita. Gerakan-gerakan musik itu adalah:

\section{Allemande}

- Tempo cepat dalam birama biner.

- Dimulai pada not upbeat 1/8 atau 1/16.

\section{Courante}

- Temponya lebih cepat sedikit dari Al lemande.

- Biramanya terner, kadang-kadang merupakan kombinasi atau sendirisendiri antara birama 3/2 dan birama $6 / 4$.

\section{Sarabande}

- Gerakan musik yang bertempo lambat, dalam birama terner.

4. Gigue

- Biasanya merupakan gerakan terakhir dari sebuah suita.

- Temponya cepat, dalam birama terner kombinasi (6/8, 9/8 atau 12/8).

- Teksturnya seringkali bersifat fugatis.

\section{METODE}

Pemikiran fenomenologi Maurice Merleau-Ponty dipaparkan di dalam bukunya, Phenomenology of Perception (2002/ 1945). Di dalam bukunya itu, Merleau-Ponty membedakan antara body schema dan image of the body. Untuk memahami pembedaan itu, kita harus memahami asal-usulnya dari gagasan skematisme (schematism) Kant di dalam Critique of Pure Reason.

Menurut Kant, yang disebut dengan "transcendental schema" adalah "jembatan penghubung" antara sesuatu yang abstrak (kategori) dan hal-hal yang empiris (intuisi). Dengan demikian yang disebut dengan skema sebuah konsep adalah representasi dari prosedur umum imajinasi untuk menyediakan sebuah konsep dengan imajinya. Jadi, skemata (schemata) adalah aturan atau prosedur yang keluar dari imajinasi dan membentuk konstruksi imaji selaras dengan hal-hal yang konseptual. Dengan demikian, imaji itu adalah "objects of awareness", sementara itu skemata adalah kemampuan dalam "membuat sketsa" terlebih dahulu dan menstruktur awareness of objects. Penerapan konsep bergantung pada sejenis tindakan. Apa yang hakiki di dalam konsep body schema itu adalah 
gagasan mengenai kemampuan yang siap untuk mengantisipasi dan menyatukan dunia berdasarkan suatu konsep dan juga berdasarkan pembentukan pikiran dan judgments.

Metode ini dikaitkan dengan suita yang seringkali tidak hanya berisi empat gerakan - yang isinya merupakan gerakan-gerakan musik obligatoris seperti dipaparkan pada pendahuluan. Lebih sering ia merupakan sebuah bentuk musik besar yang memiliki lebih dari empat gerakan - bisa mencapai 10 gerakan. Untuk mencapai jumlah yang lebih dari empat gerakan, ada sejumlah musik tarian yang dimasukkan ke dalam suita tersebut. Ada sejumlah cara untuk memasukkan gerakan-gerakan musik yang "opsional" tersebut. Cara pertama adalah memasukkan sejumlah gerakan musik tari tertentu di antara gerakan sarabande dan gigue. Sedangkan cara kedua adalah dengan memasukkan sejumlah gerakan musik tari tertentu setelah gigue.

Cara pertama: memasukkan sejumlah gerakan musik tari tertentu di antara gerakan sarabande dan gigue. Jumlah "selingan" ini terdiri dari dua sampai empat gerakan tarian, tergantung pada komponis. Gerakangerakan musik tari itu adalah:

\section{Minuet}

- Sebuah gerakan musik dengan birama $3 / 4$, bergaya anggun.

- Di dalam banyak suita, ada dua minuet. Minuet pertama dimainkan dengan pengulangan, yang kemudian diikuti oleh minuet kedua juga dengan pengulangan. Setelah itu minuet pertama (da capo) dimainkan kembali tanpa pengulangan.

2. Bourée

Sebuah gerakan musik yang yang cepat dan ringan dalam birama $3 / 4$.

3. Polonaise
- Sebuah gerakan musik dalam birama 3/4 yang dibangun dari perputaran dua birama - dua birama itu diulangulang.

- Ketukan yang paling kuat diberikan pada ketukan pertama dari birama pertama.

4. Gavotte

- Sebuah gerakan musik berbirama 4/4 atau dalam birama-birama yang sejenisnya.

- Dimulai dengan ketukan ketiga dari birama gantung.

Cara kedua adalah dengan memasukkan sejumlah gerakan musik tari tertentu setelah gigue. Gerakan-gerakan musik itu adalah:

1. Siciliana

- Sebuah gerakan musik berbirama $6 / 8$ atau $12 / 8$.

- Seringkali dalam tangganada minor, dengan suasana yang "muram".

2. Passepied

- Sebuah gerakan musik yang mengambil inspirasinya dari tarian istana Perancis dalam birama $3 / 8$ atau 9/8.

- Dimulai pada ketukan terakhir dari birama gantung.

- Musiknya bersifat ringan dengan rasa gerakan yang sangat kuat - dikatakan bahwa gerakan musik ini lebih cepat daripada minuet, tetapi masih "kurang greget-nya" daripada gigue.

3. Rigaudon

Musiknya mirip dengan bourée, tetapi memiliki ritme yang lebih sederhana dengan frase yang teratur (yang paling umum: frase delapan birama).

4. Loure

- Namanya itu berasal dari nama alat musik Loure.

- Dikenal juga sebagai "gigue lente" 
atau "gigue yang lambat" - tempo loure bisa lambat, dan juga bisa sedang.

- Musiknya berbirama terner, tetapi lebih sering dalam birama yang biner.

5. Passacaglia

Dikatakan bahwa tarian passacaglia diciptakan setelah adanya musik passacaglia. Oleh sebab itu keterangan mengenai passacaglia justru berbeda dengan keterangan-keterangan mengenai gerakan tari lainnya. Singkatnya, gerakan tarian passacaglia (justru) berasal dari musik passacaglia.

6. Chaconne

Chaconne memang dikenal sebagai musik instrumental, tetapi sesungguhnya Chaconne berasal dari musik tarian. Chaconne muncul di kebudayaan Spanyol abad ke-16; dikatakan bahwa tarian ini berasal dari "Dunia Baru" (daratan Amerika). Tarian ini berciri gerakannya cepat; tetapi setelah menjadi musik instrumental, Chaconne menjadi musik dengan birama terner dan lambat.

7. Musette

- Adalah nama alat musik bagpipe yang kecil.

- Tarian Musette adalah tarian yang diciptakan untuk meniru permainan alat musik ini.

8. Canario

- Adalah tarian populer dari masa Renaisans (Eropa abad ke-16 dan 17).

- Tarian ini untuk dimainkan berpasang-pasangan dengan tempo yang cepat dan berapi-api musiknya. Itulah sebabnya, musik canario memiliki tempo yang cepat.

9. Forlane

Gerakan musiknya bersifat cepat dengan birama biner $6 / 8$.

10.Tambourin

- Tambourin adalah sebuah karya musik yang meniru bunyi drum (Abad Pertengahan).

- Tambourin sebagai sebuah karya tari adalah tarian yang berasal dari Perancis dengan tempo yang "hidup" dan dalam birama biner. Itulah sebabnya, tambourin memiliki tempo yang "hidup" dan berbirama biner.

\section{HASIL DAN PEMBAHASAN}

\section{Tari Yang Menjadi Asal-Usul Gerakan} Musik

Mengapa suita disebut sebagai sebuah musik yang merupakan hasil penggayaan atas sejumlah gerakan tari (stylized dance music)? Hal ini disebabkan karena apa yang menjadi gerakan musik di dalam suita berasal-usul dari gerakan tari yang faktual dan aktual. Ada sejumlah tarian yang menjadi asal-usul pembentukan gerakan musik di dalam suita. Tari-tari itu adalah:

1. Allemande:

- Istilah ini berasal dari bahasa Perancis; artinya: "Jerman".

- Allemande adalah sebuah tarian yang anggun dalam birama $4 / 4$.

2. Courante/ Corrente:

- Istilah ini berasal dari bahasa Perancis, courant, yang artinya "berlari".

- Courante sebagai sebuah tarian Perancis sifatnya "hidup" dan dalam birama 3/4, sedangkan corrente sebagai sebuah tarian Italia sifatnya cepat dalam birama 3/4.

3. Sarabande:

Adalah sebuah tarian yang berasal dari Spanyol, berbirama 3/4

4. "Selingan":

Tari-tari yang menjadi sumber inspirasi bagi gerakan musik itu adalah:

a. Minuet (Menuetto):

Sebuah tarian berbirama 3/4, bergaya anggun.

b. Bourée 
Sebuah tarian yang yang ringan dalam birama $4 / 4$.

c. Polonaise

Sebuah tarian dalam birama 3/4 yang dibangun dari perputaran dua birama.

d. Gavotte

Sebuah tarian berbirama 4/4 atau dalam birama-birama yang sejenisnya.

5. Gigue/ Giga/ Jig:

Sebuah tarian yang berasal dari Inggris

6. Siciliana (Sicilienne):

Sebuah tarian berbirama $6 / 8$ atau $12 / 8$

7. Passepied:

- Sebuah tarian yang berasal dari tarian istana Perancis dalam birama $3 / 8$ atau $9 / 8$.

- Tariannya bersifat ringan dengan rasa gerakan yang sangat kuat - dikatakan bahwa tarian ini lebih cepat daripada minuet, tetapi masih "kurang gregetnya" daripada gigue.

8. Rigaudon

- Adalah sebuah tarian yang berasal dari Perancis; ditarikan berpasangpasangan.

- Berasal dari tarian rakyat Perancis selatan (abad ke-17), kemudian menjadi tarian istana pada masa pemerintahan Raja Louis XIV.

- Kepopulerannya merosot setelah ada ballroom dance pada abad ke-18.

9. Loure

- Berasal dari Normandia, Perancis.

- Namanya itu berasal dari nama alat musik Loure.

- Dikenal juga sebagai "Gigue lente" atau "Gigue yang lambat" - tempo Loure bisa lambat, dan juga bisa sedang.

11.Passacaille/ Passacaglia

Tarian yang diciptakan, justru asalusulnya adalah dari musik- diciptakan dengan gerakan-gerakan yang mengacu pada musik yang ada: lebih dulu ada musik passacaglia-nya, baru kemudian diciptakan tariannya.

12. Chaconne

Chaconne memang dikenal sebagai musik instrumental, tetapi sesungguhnya Chaconne berasal dari musik tarian. Chaconne muncul di kebudayaan Spanyol abad ke-16; dikata-kan bahwa tarian ini berasal dari "Dunia Baru" (daratan Amerika). Tarian ini berciri gerakannya cepat; tetapi setelah menjadi musik instrumental, Chaconne menjadi musik dengan birama terner dan lambat.

13.Musette

- Adalah nama alat musik bagpipe yang kecil.

- Tarian Musette adalah tarian yang diciptakan untuk meniru permainan alat musik ini.

14.Canario (Italia)/ Canary (Inggris)

- Adalah tarian populer dari masa Renaisans (Eropa abad ke-16 dan 17).

- Tarian ini untuk dimainkan berpasang-pasangan dengan tempo yang cepat dan berapi-api musiknya.

15.Forlane/ Furlana

- Adalah tarian rakyat Italia. Diduga, tarian ini diciptakan oleh orang-orang Slav yang merupakan minoritas di sana.

- Tarian ini bersifat cepat dengan birama biner 6/8.

16. Tambourin

- Tambourin adalah sebuah karya musik yang berusaha untuk meniru bunyi drum (Abad Pertengahan)

- Tambourin sebagai sebuah karya tari adalah tarian yang berasal dari Perancis dengan tempo yang "hidup" dan dalam birama biner. 


\section{Perubahan Medium di dalam Seni}

Bagaimana bisa terjadi pembentukan sebuah gerakan musik di dalam suita? Jika dimulai dengan ungkapan yang sederhana, bisa dikatakan dengan mudah bahwa dalam menciptakan gerakan musik yang ada, seorang komponis diinspirasikan oleh tari-tari yang ia temui. Hal ini memang sulit untuk dibantah. Hal ini analog dengan terjadinya musik yang bersifat patriotis; dalam musik yang bersifat patriotis, seorang komponis diinspirasikan oleh kejadian kepahlawanan yang terjadi di sekitarnya. Hal ini dapat dipahami dengan cara berpikir terjadinya seni secara umum:

Pada mulanya diperkirakan bahwa hakekat penciptaan seorang seniman adalah karena ia meniru apa yang ada di luarnya. Inilah yang dikenal secara luas sebagai teori imitasi. Dengan teori imitasi sangat mudah untuk dipahami bahwa ketika seorang pelukis melukis pemandangan alam, apa yang dilukisnya itu adalah hasil dari "pemotretan" atas sesuatu yang terdapat di luar dirinya - dalam hal ini: pemandangan alam yang ia temui. Dalam bidang seni lukis, teori imitasi menjadi goyah setelah ditemukan karyakarya lukis yang "secara garis besar" menunjukkan "hasil potret" seniman atas sesuatu yang terdapat di luar dirinya, tetapi "hasil potret" itu "begitu jauh" dari faktanya; misalnya: lukisan beraliran kubisme atau surealisme. Dengan hasil yang "jauh" daripada aslinya, apa yang ditiru atau "dipotret" oleh seniman?

Inilah kekurangan dari teori imitasi, dan kekurangan ini diluruskan oleh teori ekspresi. Seorang seniman ketika ia "menenerjemahkan" apa yang ada di hadapnnya, adalah bukan dengan meniru apa yang ada, melainkan dengan mengekspresikan apa ditangkapnya itu. Jadi, memang ia menangkap apa yang ada dihadapannya itu, tetapi setelah itu ia tidak memindahkan begitu saja apa yang ditangkapnya itu. Apa yang ditangkapnya itu ia "keluarkan" kembali dalam bentuk yang lain dengan segala nilai yang dimiliki sang seniman. Teori ini sangat sahih untuk menjelaskan kejadian musik patriotis seperti yang disebutkan di atas. Sebab, sangat sulit untuk menjelaskan apa yang diungkapkan oleh seorang komponis ketika ia mendapat sebuah objek sementara objek itu tidak bisa "diterjemahkan dengan gamblang" seperti halnya hasil karya lukis. Ini misalnya terjadi di dalam komposisi “Overture to 1812" karya komponis Rusia, P.I. Tchaikovsky; apa yang diterjemahkan oleh Tchaikovsky dalam bentuk nada-nada, peristiwa kekalahan Napoleon oleh Rusia pada tahun 1812? Bagaimana "menerjemahkan" peristiwa faktual dalam bentuk nadanada?

Kejadian yang sama dalam kasus Tchaikovsky juga terjadi dalam kasus musik suita. Gerakan musik di dalam suita adalah bukan "potret" seorang komponis atas tari yang aktual dan faktual, melainkan merupakan "penerjemahan" komponis atas tari yang aktual dan faktual itu. Dengan istilah "penerjemahan" dan bukan "potret" itu, menjadi lebih mudah dipahami mengapa gerakan musik yang ada itu bahkan tidak bisa atau minimal sangat sulit untuk digunakan mengiringi tari yang aktual dan faktual - padahal gerakan musik itu berasal dari tari tersebut.

Formulasi permasalahan ini belum menyelesaikan masalah. Pertanyaan yang bisa diajukan untuk sampai pada tahap selanjutnya adalah: apa yang terdapat di dalam tari tersebut sehingga kemudian bisa diterjemahkan oleh seorang komponis menjadi gerakan musik? Strategi pemaparan di bawah ini adalah bahwa penulis akan memaparkan terlebih dahulu 
tari yang aktual dan faktual - berarti berbicara mengenai tari secara empiris, barulah setelah itu penulis akan berusaha menafsirkan apa yang terdapat di dalam tari secara fenomenologis.

\section{Rupa Tari}

Untuk mempersingkat ruang dan waktu, di bawah ini penulis tidak akan memaparkan semua tari yang mungkin terdapat di dalam suita. Apa yang akan penulis paparkan di bawah ini hanyalah tari-tari yang membentuk gerakan musik yang obligatoris di dalam suita. Strategi paparan yang demikian adalah sah adanya; sebab apa yang menjadi cara berpikir terjadinya gerakan musik yang obligatoris dari tari yang aktual dan faktual juga berlaku bagi gerakan musik yang opsional dari tari yang aktual dan faktual.

\section{Allemande}

Allemande berasal dari tari Renaisans abad ke-16, dengan birama biner (duple metre) dan dalam tempo yang sedang. Istilah "allemande" berasal dari kata bahasa Perancis yang artinya "Jerman"; tari itu diperkirakan disukai oleh orang-orang Jerman masa itu.

Tarinya diperkirakan berbentuk sepasang penari menari berpasangan, menjulurkan tangan-tangan mereka ke depan, bergerak bolak-balik sepanjang ruangan, berjalan tiga langkah, kemudian berdiri di atas satu kaki. Dalam versinya yang lebih cepat, allemande courante, para penari melangkah lebih melayang dalam tiga langkah dan satu kali lompatan.

Allemande dipandang sebagai sebuah tarian yang agak serius. Ada penulis yang mengatakan bahwa allemande harus ditarikan dan musiknya juga harus digubah, dalam gaya yang kaku dan seremonial. Sementara penulis yang lain menambahkan bahwa allemande itu mengekspresikan hiburan dan kegembiraannya dalam suasana yang tenang dan tertata.

Para komponis Perancis abad ke-17 bereksperimen dengan allemande. Mereka mengubahnya menjadi berbirama empat-an (quadruple meter) dan temponya lebih "lebar". Segi-segi lain yang mencolok adalah pada penggunaan sebuah upbeat dari not seperdelapan, ketiadaan sinkopasi, penggunaan motif-motif musik yang kecil dalam membangun bagian besar, dan kontras tangganada.

\section{Courante}

Courante/ corrente/ coranto/ corant adalah sebuah tarian berbirama terner (triple meter) dari era akhir Renaisans dan awal Barok. Dalam musik Bach, dibedakan antara "courante" dan "corrente"; "courante" digunakan untuk musik tarian yang bergaya Perancis \% yang akan terus berkembang lebih lanjut. Sedangkan "corrente" adalah musik tariannya yang bergaya Italia. Corrente memiliki tempo lambat, sebaliknya courante memiliki tempo yang cepat.

Secara harafiahnya, courante berarti "berlari". Pada akhir era Renaisans courante ditarikan dengan berlari-lari dan langkah yang melompat-lompat. Dikatakan bahwa gerakan courante dipenuhi oleh hasrat dan suasana hati yang gembira; ada gambaran mengenai kerinduan dan sekaligus pemenuhan dari kerinduan itu.

\section{Sarabande}

Sarabande pertama kalinya dikemukakan keberadaannya di dalam sebuah puisi di Amerika Selatan karya Fernando de Guzmán Mejía pada tahun 1539; di sana ia disebut zarabanda. Tarian itu sangat populer pada abad ke-16 dan 17 di daerah-daerah koloni Spanyol - sebelum akhirnya dibawa 
ke daratan Spanyol itu sendiri.

Tarian itu dilarang berulang kali karena dianggap terlalu "cabul". Tarian itu kemudian menyebar ke Italia pada abad ke17, dan akhirnya masuk Perancis menjadi tarian istana dengan tempo yang lambat.

\section{Gigue}

Gigue atau "giga" (Italia) adalah sebuah tarian era Barok yang berasal dari Inggris, "jig", dan diimpor ke Perancis pada pertengahan abad ke-17. Tarian ini sifatnya "hidup".

Di dalam drama-drama Perancis, adalah suatu hal yang biasa untuk mengakhiri pertunjukan dengan sebuah gigue yang lengkap dengan musik dan tarian. sedangkan tentang asal-usul "keItalia-annya", diperkirakan istilah giga berasal dari nama ansambel pengiring yang terdiri dari alat musik gesek. Nama ansambel itu adalah "giga".

Tarian ini tidak pernah menjadi tarian istana, tetapi ditarikan oleh para bangsawan pada acara-acara yang bersifat sosial.

\section{Symbolic Gestures dalam Tari dan Ekspresi di dalam Musik}

Apa yang diekspresikan oleh komponis ketika ia menggubah gerakan musik yang berasal dari tari-tari tertentu? Menurut penulis, untuk memahami pembentukan gerakan musik yang berdasarkan sebuah tari, hal ini harus dilakukan dengan mengacu pada tari sebagai symbolic gestures. Untuk menjelaskan gagasan tersebut, penulis melakukan hal ini dengan cara mengelaborasi paparan di atas mengenai tari-tari yang membentuk gerakan musik yang obligatoris.

\section{Allemande}

Dalam menciptakan gerakan musik allemande, komponis "menyerap" gerakan tari yang diperkirakan berbentuk sepasang penari menari berpasangan, menjulurkan tangan-tangan mereka ke depan, bergerak bolak-balik sepanjang ruangan, berjalan tiga langkah, kemudian berdiri di atas satu kaki. Selain itu, untuk menghasilkan gerakan musik yang lebih cepat, komponis "menyerapnya" pada allemande courante, dimana para penari melangkah lebih melayang dalam tiga langkah dan satu kali lompatan.

Jika para ahli tari masih memperdebatkan hakekat yang sesungguhnya dari allemande, para komponis tidak mempermasalahkan jika (gerakan musik) allemande haruslah bergaya kaku dan seremonial, ataukah mengekspresikan hiburan dan kegembiraan dalam suasana yang tenang dan tertata. Bagi komponis, yang terpenting adalah terkeluarkannya gagasangagasan musik yang ada di dalam dirinya.

\section{Courante}

Gerakan musik courante sangat mirip dengan apa yang ada di dalam tari courante. Secara harafiahnya, courante berarti "berlari". Pada akhir era Renaisans courante ditarikan dengan berlari-lari dan langkah yang melompat-lompat. Dikatakan bahwa gerakan courante dipenuhi oleh hasrat dan suasana hati yang gembira; ada gambaran mengenai kerinduan dan sekaligus pemenuhan dari kerinduan itu. Pemikiran ini kemudian diterjemahkan dengan "pelepasan" batasan-batasan yang ada di dalam allemande; musik courante dirasakan sebagai musik yang merupakan pelepasan dari penundaan emosi yang terdapat di dalam allemande.

\section{Gigue}

Gerakan musik gigue sangat tepat ditempatkan pada akhir dari musik suita. Hal ini berangkat dari suatu fakta bahwa 
tari gigue bersifat "hidup". Selain itu, hal itu juga dibangun oleh gambaran sejarah yang diciptakan oleh istilah gigue itu sendiri.

Di dalam drama-drama Perancis, adalah suatu hal yang biasa untuk mengakhiri pertunjukan dengan sebuah gigue yang lengkap dengan musik dan tarian. sedangkan tentang asal-usul "keItalia-annya", diperkirakan istilah giga berasal dari nama ansambel pengiring yang terdiri dari alat musik gesek. Nama ansambel itu adalah "giga".

Dengan demikian gerakan musik gigue bisa berfungsi pas sebagai gerakan terakhir dari musik suita; sifat gerakan musiknya "hidup" dan dengan musik tersebut tergambar suasana akhir dari sebuah pertunjukan.

Dalam semua gerakan musik, para komponis menyerap tari yang ditemuinya. Hasil serapan itu diolah di dalam dirinya, dinternalisir dan akhirnya "dikeluarkan" kembali dalam bentuk yang lain. Dengan imajinasinya yang sangat tinggi, gambaran tari yang ditemuinya sebelumnya "dialihwahanakan" menjadi nada-nada yang berbunyi di kepalanya - yang tadinya merupakan sebuah gerakan tubuh manusia di hadapannya, dialihwahanakan menjadi gerakan nada-nada di kepalanya. Dibangun dalam suasana budaya yang sama, penonton akan memahami apa yang digubah oleh komponis tersebut.

Menurut pengalaman penulis, pemain musik di Indonesia tidak terlalu mempermasalahkan hakekat dari gerakan musik yang ada. Bahkan tidak mengherankan bila ada pemusik yang tidak memahami asal-usul gerakan musik itu dari tari. Bagi sebagian besar pemusik di Indonesia, yang penting dipahami hanyalah bahwa courante lebih cepat daripada allemande, sarabande memiliki tempo yang lambat, dan gigue harus bertempo paling cepat dibandingkan dengan ketiga gerakan sebelumnya. Hal ini disebabkan karena perbedaan budaya.

Orang-orang Barat bisa memahami hakekat gerakan musik gigue, misalnya, yang terhubung dengan tari gigue. Hal ini disebabkan karena mereka dibangun dalam suasana budaya yang berbeda dengan orang Indonesia. Jadi, ketika seorang pemain musik memainkan gerakan musik gigue, misalnya, para penonton mendapatkan "feel" dari gerakan musik itu karena dibangun dari pemahaman mengenai tari gigue. Dengan demikian bisa dikatakan bahwa dalam konteks praktek musik, indahnya gerakan musik yang ada dibangun dari sinergi atau proses timbal-balik antara pemain musik yang memahami hakekat gerakan musik karena memahami sejarah gerakan musik tersebut dan penonton yang memahami hakekat gerakan musik karena memahami sejarah gerakan musik tersebut dari tari-tari tertentu.

\section{SIMPULAN}

Paparan di atas menunjukkan cara berpikir alih wahana dari tari menjadi musik. Dari paparan itu terlihat bahwa terjadinya alih wahana itu melalui sejumlah langkah-langkah sebagai berikut: pertama, ada symbolic gestures di dalam tari. Apa yang menjadi forma di dalam medium tari-yang hadir dalam bentuk gerakan-gerakan tubuh manusia - ditangkap oleh komponis. Apa yang ditangkapnya itu kemudian diekspresikan di dalam bunyi-bunyian yang tertentu.

Mengapa kejadian ini begitu sulit diterangkan, walaupun jelas ada di depan mata, hal ini disebabkan karena selama ini para peneliti di dalam bidang musik tidak memanfaatkan pemikiran fenomenologi dari Merleau-Ponty. Pemikiran Merleau- 
Ponty yang utamanya berbicara mengenai struktur fenomenologi persepsi, ternyata secara jitu berhasil menguak proses kreatif seorang komponis dalam "menyerap" karya yang bukan merupakan bidangnya. Apa yang "diserapnya" itu kemudian "diekspresikan" bukan dalam bentuk katakata, melainkan dalam bentuk bunyi-bunyi yang tertentu. Hasilnya adalah sebuah karya seni yang berakar dari medium seni yang bukan asal dirinya: musik tarian.

\section{Catatan Akhir}

${ }^{1}$ Di dalam sejarah musik Barat terdapat tujuh era musik, yaitu: Jaman Kuno, Abad Pertengahan, Renaisans, Barok, Klasik, Romantik dan Abad ke-20.

${ }^{2}$ Misalnya, piano adalah alat musik yang utama pada era Romantik.

${ }^{3}$ Terdapat gaya-gaya dinamik musik yang berbeda jelas antara era Barok, Klasik dan Romantik, misalnya. Musik pada era Barok memiliki dinamik musik yang "rata" dan jika mengalami perubahan akan naik/ turun secara "bertangga-tangga" (terraced dynamics); musik pada era Klasik bisa mengalami perubahan dinamik bertahap (dikenallah perubahan dinamik crescendo/ decrescendo); sedangkan musik pada era Romantik bisa mengalami perubahan dinamik secara tiba-tiba (perubahan tibatiba cukup ditandai oleh tulisan "sub."/ "subito" ["tiba-tiba"]).

${ }^{4}$ Sonata dan sonata form adalah bentuk musik yang paling berkembang pada era Klasik, misalnya.

${ }^{5}$ Untuk memahami musik abad ke-20, harus dipahami keterkaitan yang erat musik tersebut dengan situasi sosial, politik dan ekonomi yang berkembang pada abad ke-20, misalnya.

${ }^{6}$ Suite (Inggris), Suite (Jerman).

${ }^{7}$ Dengan menyebut istilah "album" di sini, hal ini secara jelas menunjukkan bahwa permasalahan suita soalnya adalah pada permasalahan bentuk musik, dalam hal ini bentuk musik yang besar, yang bisa diperbandingkan dengan sonata, misalnya.

${ }^{8}$ Ini adalah bentuk musik kecil yang telah disebutkan di atas. Untuk selanjutnya, penulis hanya akan menggunakan istilah teknis "gerakan musik". (Penggunaan istilah "bentuk musik kecil" hanyalah sebagai pengantar untuk memahami saja.)

"Yang dimaksud dengan "fugatis" di sini adalah sebuah musik dengan suarasuara (dua suara atau lebih) yang membentuk jalinan suara yang sifatnya independen satu sama lain.

${ }^{10}$ Yang kemudian menjadi apa itu yang disebut dengan "gendered aesthetics".

\section{Daftar Pustaka}

Cooper, David (ed.)

1992 A Companion to Aesthetics. Oxford: Blackwell Publishers

Cerbone, David R.

2006 "Merleau-Ponty and the phenomenology of embodiment" dlm. Understanding Phenomenology. Chesham, Bucks: Acumen

Dickie, George

1971 Aesthetic: An Introduction. Indianapolis, Indiana: The Bobbs-Merrill Company, Inc.

Horst, Louis

1968 Pre-Classic Dance Forms: The Pavan, Minuet, Galliard, Allemand, and 10 Other Early Dance Forms. Princeton, New Jersey: A Dance Horizons Book

Merleau-Ponty, Maurice

2002 Phenomenology of Perception. (Phénomènologie de la perception [1945]). Trans. Colin Smith. London \& New York: Routledge

McFee, Graham

1992 Understanding Dance. New York: Routledge 
Rebling, Eberhard

1972 Tanz der Völker: Folkloreballett Heute. Berlin: Henschelverlag Kunst und Gesellschaft

Saw, Ruth L.

1972 Aesthetic: An Introduction. London \& Bassingstoke: The Macmillan Press Ltd.

\section{Scruton, Roger}

1983 The Aesthetic Understanding. Manchester: Carcanet Press 